\title{
Racial/Ethnic Health Disparity in the U.S.: A Decomposition Analysis
}

\author{
Kajal Lahiri * (1) and Zulkarnain Pulungan \\ Department of Economics, University at Albany—SUNY, Albany, NY 12222, USA; zpulungan@albany.edu \\ * Correspondence: klahiri@albany.edu
}

Citation: Lahiri, Kajal, and Zulkarnain Pulungan. 2021. Racial/Ethnic Health Disparity in the U.S.: A Decomposition Analysis. Econometrics 9: 22. https:// doi.org/10.3390/econometrics9020022

Academic Editor: In Choi

Received: 31 December 2020

Accepted: 27 April 2021

Published: 6 May 2021

Publisher's Note: MDPI stays neutral with regard to jurisdictional claims in published maps and institutional affiliations.

Copyright: (c) 2021 by the authors. Licensee MDPI, Basel, Switzerland. This article is an open access article distributed under the terms and conditions of the Creative Commons Attribution (CC BY) license (https:/ / creativecommons.org/licenses/by/ $4.0 /)$.

\begin{abstract}
Following recent econometric developments, we use self-assessed general health on a Likert scale conditioned by several objective determinants to measure health disparity between nonHispanic Whites and minority groups in the United States. A statistical decomposition analysis is conducted to determine the contributions of socio-demographic and neighborhood characteristics in generating disparities. Whereas, $72 \%$ of health disparity between Whites and Blacks is attributable to Blacks' relatively worse socio-economic and demographic characteristics, it is only $50 \%$ for Hispanics and $65 \%$ for American Indian Alaska Natives. The role of a number of factors including per capita income and income inequality vary across the groups. Interestingly, "blackness" of a county is associated with better health for all minority groups, but it affects Whites negatively. Our findings suggest that public health initiatives to eliminate health disparity should be targeted differently for different racial/ethnic groups by focusing on the most vulnerable within each group.
\end{abstract}

Keywords: heteroskedastic ordered probit; BRFSS data; Blinder-Oaxaca decomposition; racial/ethnic discrimination; college education

\section{Introduction}

The disparity in health between racial/ethnic groups in the United States is welldocumented. For example, Blacks have much worse general health compared to nonHispanic Whites. Health disparity in the U.S. along multiple dimensions was considered one of the challenging goals of Healthy People 2020 (U.S. Department of Health and Human Services (US-DHHS) 2020): To achieve health equity, eliminate disparities, and improve the health of all groups. This study identifies the separate role of socio-economic and neighborhood factors in perpetuating health disparity between Whites and other racial/ethnic groups in the U.S. ${ }^{1}$

Rawls' First Principle of Justice (Rawls 1971) requires that all individuals should have the same opportunity to achieve their potential health; see Bommier and Stecklov (2002). An egalitarian viewpoint of social justice requires that people in equal need of health care should be treated equally, irrespective of characteristics, such as income, place of residence, race, and so forth. There seems to be a broad consensus among the health policy analysts that existing socioeconomic inequality in health is inequitable and unjust, and is inconsistent with the Institute of Medicine (2002) objective of eliminating of health disparity-any difference in health after adjusting for health care needs. This definition recognizes that factors, such as income may be mediators of disparity in health and health care. ${ }^{2}$

A large number of studies have reported that socioeconomic status (SES) is a key factor affecting health and health disparity (see, for example, Adler and Newman 2002; Cutler and Lleras-Muney 2006; Adams et al. 2003; Cutler et al. 2006; Deaton 2006). Individuals who live in poor neighborhoods tend to have poor health (see Ecob and MacIntyre 2000; Diez-Roux et al. 1999). There are four broad pathways-health care, environmental exposure, health behavior, and chronic stress-through which SES affects health (Adler and 
Ostrove 1999). As SES is an important mediator for health, studying health disparity cannot be separated from studying disparity in SES.

Many studies have debated whether higher income inequality in a society is associated with lower average health. Van Ourti et al. (2006) show that when the relationship between income and health is concave, proportional income growth increases average health, and rising income inequality reduces average health. Wilkinson and Pickett (2006) compile results from 155 published peer-review papers about the relationship between income inequality and population health. About seventy percent of the results suggest that health status is lower in societies where income is unequal. The proponents of the association between income inequality and health are, for example, Wilkinson (1992), Kennedy et al. (1998), Soobader and LeClere (1999), and Subramanian and Kawachi (2003, 2004, 2006).

However, Deaton and Lubotsky (2003) found that after controlling for the racial composition of the population in a city, the effect of income inequality on health disappears. They argue that the higher the percentage of minorities (e.g., Blacks), the higher the city's income inequality.

Numerous studies on measuring health and health inequality have focused on mortality rates, prevalence of diseases/risk factors, psychological morbidity, quality of or access to health care services, and health care utilization rates. ${ }^{3}$ In addition to looking at these factors, in this study, we focus on health more generally, which is a health measure based on self-assessed health (SAH) status. SAH is defined as a response to the survey question on a Likert scale, "Would you say that in general your health is: excellent, very good, good, fair, or poor?" (Centers for Disease Control and Prevention (CDC) 1999-2014).

SAH is a comprehensive measure of overall health status. Idler and Benyamini (1997) show that SAH has strong predictive validity for mortality. Sickles and Taubman (1997) compiled results from worldwide studies on the association between self-assessed health and mortality, and reported that a lower SAH level is associated with higher mortality odds. Manor et al. (2001) found that SAH has a strong association with longstanding illness. Furthermore, Lahiri et al. (1995) show that SAH is a useful predictor of the severity of disease and disability. Humphries and Doorslaer (2000) found that health inequality calculated based on SAH status gives similar results to the inequality calculated based on a more objective health indicator (viz. McMaster Health Utility Index). Safaei (2007) finds SAH to be statistically more reliable than binary chronic conditions to measure overall health.

The primary goals of this study are three-fold. First, we measure the health of different racial/ethnic groups based on SAH as conditioned by socio-demographic characteristics. Second, we identify factors contributing to the disparity between Whites and each of the minority groups, and our final goal is to decompose the disparity into socioeconomic and neighborhood characteristics. The 2013 Health Disparities \& Inequalities Report by the Centers for Disease Control and Prevention Centers for Disease Control and Prevention (CDC) (2013) emphasized the importance of identifying factors that lead to health disparities among racial, ethnic, geographic, socioeconomic, and other groups so that health equity barriers can be removed.

\section{Data}

The data used in this study are obtained from the Behavioral Risk Factor Surveillance System (BRFSS) over 1999-2014 with 1,212,890 sample observations. Every year health departments of all states, with technical and methodological assistance from CDC, conduct monthly telephone interviews on randomly selected non-institutional adults aged 18 years or older. The surveys are developed and conducted to monitor the major behavioral risks associated with premature morbidity and mortality in the adult population. In addition to BRFSS data, we also use information from the Area Resource File (ARF) 2008 release (Health Resources and Services Administration 2009). ARF contains information on health resources, socioeconomic, demographic, and environmental characteristics of each of the 
U.S. counties. Missing values were imputed using the multiple-imputation method of Rubin (1987) and Schafer (1997).

Racial/ethnic groups included in the analysis are White (refers to non-Hispanic White), Black (refers to non-Hispanic Black), Hispanic (refers to Hispanic origin), Asian (refers to non-Hispanic Asian and Pacific Islander), and AIAN (refers to American Indian and Alaska Native). The descriptive statistics from the sample are presented and summarized in the Appendix A (Table A1).

\section{Methods}

The decomposition technique proposed simultaneously by Blinder (1973) and Oaxaca (1973) is the most common method used to identify factors contributing to disparity, and quantify each factor's contribution. The technique utilizes the differences in the coefficient estimates from linear regression and the average difference in the factors or covariates (endowments). Part of the disparity attributable to the differences in the coefficient estimates is often considered direct discrimination. Whereas, the part attributable to the differences in the average factors is considered indirect discrimination. Gomulka and Stern (1990) and Fairlie $(1999,2005)$ extended the Oaxaca-Blinder technique to be applied to a binary outcome where the coefficients are estimated using the Logit or Probit model. Wenzlow et al. (2004) use this technique in measuring the contributions of income and wealth to the disparity in the prevalence of "poor" and "fair" health between non-Hispanic Whites and other racial/ethnic groups. It is well-known that the dichotomization of selfassessed health status removes the variation across categories. The measures of health and health inequality are sensitive to the cut-point chosen.

Using South Africa data, Charasse-Pouélé and Fournier (2006) estimate an ordered Probit model and calculate the average predicted probability of each SAH level to be used as an estimate of the prevalence at that level. They decompose White-African disparity in the prevalence of SAH levels "very poor", "poor", "average", and "good" by extending the Oaxaca-Blinder technique in an ordered Probit model framework. The problem with this approach is that the contributions of endowments (indirect discrimination) and coefficients (direct discrimination) to the disparity vary across SAH levels. Another problem of this approach is non-linearity that requires some approximations and/or simulations.

Our study decomposes disparity in the health index estimated based on self-assessed health conditional on other factors. The SAH is transformed into a cardinal measure subject to a normalization using the ordered Probit model (McKelvey and Zavoina 1975), following the same procedures as in Cutler and Richardson $(1997,1998)$ and Groot $(2000)$. The predicted value from the model is defined as the estimated health index.

The disparity in the average estimated health index between non-Hispanic Whites and each of the minority groups are decomposed into its determinants. The estimated health index can capture the variation across all SAH levels and avoid the non-linearity problem. The explanatory variables are socio-demographic and neighborhood factors. We also include the interaction between each variable and the racial/ethnic dummies to capture the differences in the coefficients needed for an appropriate decomposition analysis. Based on this specification, we have 5 sets of coefficient estimates that are comparable to each other. If we estimate the model separately for each racial/ethnic group, the coefficient estimates and the predicted values for each group would not be comparable with those of the other groups because the location and scale parameters in an ordered Probit model are not identifiable. We estimate the model with heteroskedasticity in the error term to control for possible heterogeneity in self-assessed health. ${ }^{4}$ Using the coefficient estimates and average endowments for each group, we apply the Oaxaca-Blinder technique in decomposing between-group health disparity into its components. 
The procedure can be written as follows. Define a vector of explanatory variables as $\mathbf{x}=\left(x_{1}, x_{2}, \ldots, x_{\mathrm{K}}\right)$, and write an equation to be estimated using ordered Probit model as follows:

$$
\begin{gathered}
h_{i}^{*}=\alpha^{w}+D^{b} \alpha^{b}+D^{h} \alpha^{h}+D^{a} \alpha^{a}+D^{a i} \alpha^{a i}+\mathbf{x}_{i} \boldsymbol{\beta}^{w}+ \\
\left(D_{i}^{b} \mathbf{x}_{i}\right) \boldsymbol{\beta}^{b}+\left(D_{i}^{h} \mathbf{x}_{i}\right) \boldsymbol{\beta}^{h}+\left(D_{i}^{a} \mathbf{x}_{i}\right) \boldsymbol{\beta}^{a}+\left(D_{i}^{a i} \mathbf{x}_{i}\right) \boldsymbol{\beta}^{a i}+s\left(\mathbf{z}_{i}, \boldsymbol{\eta}\right) \varepsilon_{i} \\
h_{i}^{s}=j \Leftrightarrow \mu_{j} \leq h_{i}^{*} \leq \mu_{j+1} \text { for } j=0,1,2, \ldots, m-1 \\
\mu_{0}=-\infty \text { and } \mu_{m}=+\infty \\
i=1,2, \ldots, n
\end{gathered}
$$

where $h^{*}$ is unobserved underlying health index; $h^{s}$ is self-assessed health status; $\left(\alpha^{w}, \beta^{w}\right)$, $\left(\alpha^{b}, \beta^{b}\right),\left(\alpha^{h}, \beta^{h}\right),\left(\alpha^{a}, \beta^{a}\right)$, and $\left(\alpha^{a i}, \beta^{a i}\right)$ are vectors of coefficients for Whites, Blacks, Hispanics, Asians, and AIANs respectively; $D^{b}, D^{h}, D^{a}$, and $D^{a i}$ are dummies for Blacks, Hispanics, Asians, and AIANs respectively; $\mu=\left(\mu_{1}, \ldots, \mu_{m-1}\right)$ is a vector of thresholds to be estimated together with the vectors of coefficients; $\varepsilon_{i}$ is the error term and is assumed to be normally distributed; $s\left(\mathbf{z}_{i}, \boldsymbol{\eta}\right)=\sigma \sqrt{\left(1+\exp \left(\mathbf{z}_{i} \boldsymbol{\eta}\right)\right)}$ is a scale function with parameter $\eta$ to control for heteroskedasticity; $\mathbf{z}_{i}$ is a vector of variables that affects the variance of the error term; $n$ is the number of observations; and $m$ is the number of categories of self-assessed health status.

Using the coefficient estimates from Equation (1), we can write the average predicted health (average estimated health index) for each racial/ethnic group as follows:

$$
\begin{gathered}
\overline{\hat{h}}_{\text {white }}^{*}=\hat{\alpha}^{w}+\overline{\mathbf{x}}_{w} \hat{\boldsymbol{\beta}}^{w} \\
\overline{\hat{h}}_{\text {black }}^{*}=\hat{\alpha}^{w}+\hat{\alpha}^{b}+\overline{\mathbf{x}}_{b}\left(\hat{\boldsymbol{\beta}}^{w}+\hat{\boldsymbol{\beta}}^{b}\right) \\
\overline{\hat{h}}_{\text {hispanic }}^{*}=\hat{\alpha}^{w}+\hat{\alpha}^{h}+\overline{\mathbf{x}}_{h}\left(\hat{\boldsymbol{\beta}}^{w}+\hat{\boldsymbol{\beta}}^{h}\right) \\
\overline{\hat{h}}_{\text {asian }}^{*}=\hat{\alpha}^{w}+\hat{\alpha}^{a}+\overline{\mathbf{x}}_{a}\left(\hat{\boldsymbol{\beta}}^{w}+\hat{\boldsymbol{\beta}}^{a}\right) \\
\overline{\hat{h}}_{\text {AIAN }}^{*}=\hat{\alpha}^{w}+\hat{\alpha}^{a i}+\overline{\mathbf{x}}_{a i}\left(\hat{\boldsymbol{\beta}}^{w}+\hat{\boldsymbol{\beta}}^{a i}\right)
\end{gathered}
$$

The disparity between non-Hispanic Whites and Blacks can be decomposed as follows:

$$
\overline{\hat{h}}_{\text {white }}^{*}-\overline{\hat{h}}_{\text {black }}^{*}=\left[\left(\overline{\mathbf{x}}_{w}-\overline{\mathbf{x}}_{b}\right) \hat{\boldsymbol{\beta}}^{w}\right]+\left[-\hat{\alpha}^{b}+\overline{\mathbf{x}}_{b}\left(-\hat{\boldsymbol{\beta}}^{b}\right)\right]
$$

The first term in brackets above represents a part of White-Black disparity due to group differences in so-called endowments (i.e., values of the covariates) as evaluated using non-Hispanic White equation. This value is considered as the contribution of indirect discrimination to the disparity, or a measure of disparity attributable to endowments. The second term represents the part arising from differences in the coefficient estimates between non-Hispanic Whites and Blacks. This value is considered as the contribution of direct discrimination to disparity, or a measure of disparity attributable to the coefficients. Each term can be decomposed into each constituent component. In this case, we calculate each component's contribution to the disparity between non-Hispanic Whites and Blacks, for example.

An equally valid method of decomposing the disparity is to use Blacks' coefficient estimates as weights for the first term and the endowments of non-Hispanic Whites as weights for the second term. This alternative method often provides different results, a familiar index problem with the Blinder-Oaxaca decomposition technique. However, in our case, the reference group is clearly defined as non-Hispanic Whites. In this case, to eliminate health disparity between non-Hispanic Whites and minorities, we need to bring the minorities to have the same generating processes of health as non-Hispanic Whites, thus, using Blacks' coefficient estimates to evaluate the contribution of the differences in endowments to the disparity makes little sense. Similarly, we can decompose the disparity between non-Hispanic Whites and each of the minority groups. 


\section{Results}

The decomposition analysis demonstrates the differences in the contribution of different factors to health inequalities between the groups. In this part, our focus is on decomposing health disparity between Whites and each of the minority groups to socio-demographic factors consisting of age, sex, race/ethnicity, marital status, education, employment status, health insurance, smoking status, and neighborhood factors, such as median county household income, income inequality, percent of Blacks in the county, percent Hispanics in the county, and a dummy for metropolitan areas.

\subsection{Coefficient Estimates}

Table 1 presents the coefficient estimates by race/ethnicity. These estimates are used in the decomposition analysis of health disparity between Whites and minority groups. In addition to individual socio-demographic variables, we also include county characteristics to capture the neighborhood's characteristics where the individual lives. These latter group of variables are median household income in the county, income Gini coefficient, percent of Blacks and Hispanics in the county population, and a dummy for the county of metropolitan areas with a population one million or more. Interestingly, the effect of these variables on health varies between racial/ethnic groups. The health of AIANs is not associated with any neighborhood characteristics. The strongest relationship between median household income and health is among Blacks, and living in a rich county is associated with better health for Blacks and Whites alike. Surprisingly, while Hispanic health is not associated with the county's median household income, Asians who live in a rich county tend to have worse health, as shown by the negative coefficient. Income inequality is associated with worse health among Whites, Hispanics, and Asians. The strongest relationship between income inequality and health is among Asians, followed by Hispanics. Interestingly, the health of Blacks, Hispanics, and Asians seem to be better in counties having more percentage of blacks, but the opposite is true with whites. Percent of Hispanics in a county population is associated with better health among Whites, Blacks, and Asians, while it is associated with poor health among Hispanics. Therefore, Hispanics who live in a county with more Hispanics tend to have worse health. Whites and Hispanics who live in metropolitan areas tend to have worse health than those who live in nonmetropolitan areas. In contrast, Blacks and Asians living in metropolitan areas tend to have better health than those who live in non-metropolitan areas. The evidence that Blacks seem to fare better in metropolitan areas have been reported by others too, see Lahiri and Kim (2021).

Table 1. Coefficient estimates used for decomposition analysis.

\begin{tabular}{cccccc}
\hline & \multicolumn{5}{c}{ Coefficient Estimate } \\
\cline { 2 - 6 } Variable & White & Black & Hispanic & Asian & AIAN \\
\hline Intercept & 2.767 & 2.633 & 2.502 & 3.509 & 2.943 \\
Age 25-29 & -0.105 & -0.038 & -0.087 & -0.066 & -0.121 \\
Age 30-34 & -0.182 & -0.126 & -0.188 & -0.143 & -0.292 \\
Age 35-39 & -0.252 & -0.207 & -0.290 & -0.208 & -0.501 \\
Age 40-44 & -0.354 & -0.433 & -0.408 & -0.334 & -0.594 \\
Age 45-49 & -0.507 & -0.701 & -0.618 & -0.462 & -0.845 \\
Age 50-54 & -0.647 & -0.913 & -0.738 & -0.548 & -0.904 \\
Age 55-59 & -0.728 & -1.029 & -0.847 & -0.703 & -1.007 \\
Age 60-64 & -0.733 & -1.063 & -0.788 & -0.792 & -0.994 \\
Age 65-69 & -0.858 & -1.115 & -0.761 & -0.708 & -1.039 \\
Age 70-74 & -1.040 & -1.108 & -0.964 & -0.780 & -1.017 \\
Age 75-79 & -1.245 & -1.253 & -1.032 & -0.846 & -0.932 \\
Age 80-84 & -1.328 & -1.214 & -1.115 & -1.118 & -1.115 \\
Age $\geq 85$ & -1.347 & -1.342 & -1.099 & -1.099 & -1.342 \\
\hline
\end{tabular}


Table 1. Cont.

\begin{tabular}{|c|c|c|c|c|c|}
\hline \multirow[b]{2}{*}{ Variable } & \multicolumn{5}{|c|}{ Coefficient Estimate } \\
\hline & White & Black & Hispanic & Asian & AIAN \\
\hline Gender $($ male $=1)$ & -0.090 & 0.175 & 0.093 & 0.042 & 0.112 \\
\hline Smoking & -0.385 & -0.250 & -0.210 & -0.278 & -0.235 \\
\hline Marital status & 0.055 & 0.057 & $0.010^{n}$ & 0.037 & 0.078 \\
\hline Grades 9-11 (Some high school) & 0.190 & 0.255 & 0.319 & $0.010^{n}$ & $0.122^{n}$ \\
\hline $\begin{array}{l}\text { Grade } 12 \text { or GED (High school } \\
\text { graduate) }\end{array}$ & 0.552 & 0.439 & 0.636 & 0.179 & 0.420 \\
\hline College 1 year to 3 years & 0.704 & 0.534 & 0.836 & 0.323 & 0.481 \\
\hline $\begin{array}{c}\text { College } 4 \text { years or more (College } \\
\text { graduate) }\end{array}$ & 1.007 & 0.733 & 1.080 & 0.540 & 0.692 \\
\hline Self-employed & 0.213 & 0.125 & 0.214 & 0.225 & 0.138 \\
\hline Out of work & -0.367 & -0.273 & -0.161 & -0.128 & -0.159 \\
\hline A homemaker & $0.002^{n}$ & -0.113 & -0.086 & -0.091 & -0.089 \\
\hline A student & 0.128 & 0.048 & 0.130 & $0.034^{\mathrm{n}}$ & $-0.037^{n}$ \\
\hline Retired & -0.266 & -0.424 & -0.319 & -0.198 & -0.568 \\
\hline Unable to work & -2.384 & -1.684 & -1.741 & -1.615 & -2.058 \\
\hline Having health plan & 0.045 & 0.107 & 0.219 & 0.134 & $0.034^{n}$ \\
\hline Income pc 10-15 & 0.176 & 0.121 & 0.248 & 0.063 & 0.129 \\
\hline Income pc 15-20 & 0.340 & 0.214 & 0.409 & 0.212 & 0.270 \\
\hline Income pc 20-25 & 0.450 & 0.298 & 0.605 & 0.244 & 0.519 \\
\hline Income pc 25-35 & 0.576 & 0.370 & 0.683 & 0.335 & 0.538 \\
\hline Income pc 35-50 & 0.680 & 0.508 & 0.810 & 0.480 & 0.796 \\
\hline Income pc 50-75 & 0.865 & 0.630 & 0.972 & 0.659 & 0.873 \\
\hline Income $\mathrm{pc} \geq 75$ & 0.939 & 0.745 & 1.105 & 0.723 & 1.079 \\
\hline County median household income & 0.035 & 0.047 & $0.002^{n}$ & -0.037 & $-0.021^{n}$ \\
\hline County income inequality & -0.217 & $-0.365^{n}$ & -0.622 & -1.173 & $-0.220^{\mathrm{n}}$ \\
\hline County percent Black & -0.045 & 0.241 & 0.140 & 0.187 & $0.021^{n}$ \\
\hline County percent Hispanic & 0.167 & 0.157 & -0.182 & 0.276 & $0.123^{n}$ \\
\hline $\begin{array}{l}\text { County of metro areas of } 1 \text { million } \\
\text { pop. or more }\end{array}$ & -0.051 & 0.036 & -0.115 & $0.020^{n}$ & $0.002^{n}$ \\
\hline
\end{tabular}

McKelvey-Zavoina $\mathrm{R}^{2}=0.46$

Note: Reference for Age group dummies is 18-24; for Education, it is grade 8 or less; and for employment, it is employed for a wage. ${ }^{\mathbf{n}}$ indicates the coefficient is not significantly different from 0 . Variables included in the scale function to control for heteroscedasticity are age, sex, race/ethnicity, annual household income, having health plan, and education level, reported in Table A1a.

\subsection{Decomposition Analysis}

Asians and Whites have the highest health indices, respectively, 0.703 and 0.699 , and AIANs and Hispanics have the lowest average health index (0.652) followed by Blacks (0.666). As the difference in average health index between Whites and Asians is very small, the focus of the decomposition analysis is on disparity between Whites-Blacks, WhitesHispanics and Whites-AIANs. Table 2 presents the summary results of the decomposition analysis of health disparity between Whites and the minority groups. More detailed analysis on the decomposition analysis is presented in Table A2 in the Appendix A. ${ }^{4}$ We now describe each component's contribution to health disparity between Whites and each of the minority groups: 
Table 2. Summary of a decomposition analysis of White-minorities health disparity.

\begin{tabular}{|c|c|c|c|c|c|c|c|}
\hline \multirow[b]{2}{*}{ Component } & & \multicolumn{2}{|c|}{ White-Black } & \multicolumn{2}{|c|}{ White-Hispanic } & \multicolumn{2}{|c|}{ White-AIAN } \\
\hline & & Endow. & Coef. & Endow & Coef. & Endow & Coef. \\
\hline Age & $(\%)$ & -18.5 & 18.1 & -24.7 & 3.6 & -13.9 & 24.7 \\
\hline Sex $($ male $=1)$ & $(\%)$ & -1.2 & -26.1 & 0.3 & -14.2 & 0.4 & -16.7 \\
\hline Smoking & $(\%)$ & 0.2 & -6.9 & -2.2 & -5.0 & 8.0 & -8.5 \\
\hline Marital status & $(\%)$ & 2.8 & -0.2 & 0.5 & 3.7 & 1.1 & -1.8 \\
\hline Education & $(\%)$ & 19.7 & 32.9 & 34.7 & -12.7 & 17.3 & 29.0 \\
\hline Employment & $(\%)$ & 21.2 & -5.2 & 1.6 & -4.4 & 20.8 & 1.8 \\
\hline Health plan & $(\%)$ & 0.8 & -11.5 & 1.5 & -17.6 & 1.0 & 1.3 \\
\hline Household income & $(\%)$ & 40.4 & 25.8 & 39.8 & -9.6 & 28.4 & -0.4 \\
\hline $\begin{array}{l}\text { County median household } \\
\text { income }\end{array}$ & $(\%)$ & 2.8 & -11.4 & 1.0 & 22.1 & 2.1 & 37.7 \\
\hline County income inequality & $(\%)$ & 0.8 & 13.1 & 1.0 & 24.8 & 0.4 & 0.2 \\
\hline County percent Blacks & $(\%)$ & 1.5 & -16.7 & 0.0 & -3.1 & 0.0 & -1.1 \\
\hline County percent Hispanics & $(\%)$ & -0.6 & 0.3 & -4.6 & 15.3 & -0.4 & 0.8 \\
\hline Metro area & $(\%)$ & 1.8 & -14.0 & 1.3 & 7.0 & -0.7 & -3.9 \\
\hline Total & $(\%)$ & 71.8 & 28.3 & 50.3 & 49.6 & 64.5 & 35.5 \\
\hline
\end{tabular}

White-Black disparity. Table 2 shows that $72 \%$ of the disparity in health between Whites and Blacks is attributable to the inferior values of the covariates like education, income, etc. (i.e., endowments) for the Blacks. This implies that by keeping the same coefficients that Blacks have, but were given the Whites' endowments, White-Black disparity could be reduced by $72 \%$. The total contribution of coefficients, often called 'discrimination', is $28 \%$. This could be the result of the disparity in the quality of health care services and treatments received by Blacks, as reported in several studies (Lee et al. 1998; Hodgson et al. 2001; Bruner et al. 2006). The result implies that with Blacks' current values of the covariates, given Whites' coefficients, health disparity between Blacks and Whites could be reduced by another $28 \%$. Among the factors contributing to Black-White disparity, income has the largest contribution, followed by education and employment status. In addition, living in a rich county, in a county with a large percentage of Blacks, or in a metropolitan area is advantageous for Blacks that could reduce White-Black disparity in health.

White-Hispanic disparity. The total contribution of endowments to White-Hispanic disparity is $50 \%$ in favor of Whites. Most of this contribution is attributable to income and education. The contribution of age to the disparity is $25 \%$ in favor of Hispanics, as expected, since Hispanics in the United States are much younger on average than Whites as presented in Table A1 of the Appendix A. The contribution of the estimated coefficient vector is $50 \%$. This means that even if Hispanics have the same endowments as Whites, Hispanics would still be lagging behind due to social discrimination. In addition to the disparity in the quality of care received by minorities, the communication barrier could also contribute to the coefficient. Fiscella et al. (2002) found that Spanish-speaking Hispanics in the U.S. are significantly less likely than non-Hispanic Whites to have physician visits. A factor with the highest contribution to the disparity is income, followed by county income inequality, county median household income, and education. In general, neighborhood characteristics are relatively more important factors contributing to Hispanic-White disparity than their contribution for the Black-White disparity. Education and income act as firewall to health shocks; in its absence the support from the neighborhood and the community becomes more important, cf. Case and Deaton (2020).

White-AIAN disparity. American Indians and Alaska Natives have the worst average health. Most of the disparity is attributable to the inferior endowments of AIANs like socio-economic and demographic characteristics. The endowments account for a $65 \%$ White-AIAN health disparity in favor of Whites. The dominant factors favoring Whites relative to AIAN are income, employment status, and education, which are the same factors 
as before. Similar to other minority groups, age has a negative contribution to the disparity. This is understandable because the life expectancy of AIANs is much lower than that of Whites. The total contribution of coefficients to the disparity is 35\% in favor of Whites, where the major contributors are median household income, age and education.

\section{Conclusions}

Following recent developments in the measurements of health and health disparity, we used self-assessed health to measure health disparity between non-Hispanic Whites and the minority groups in the U.S. A decomposition analysis was conducted to determine the contribution of different socio-demographic and neighborhood characteristics to the disparity. This is the main contribution of the paper.

We found that the effects of neighborhood and personal characteristics on health vary significantly across racial/ethnic groups. Living in a wealthy county is associated with better health for Blacks and Whites, but not for Hispanics. Income inequality is unequivocally associated with poor individual health for Whites, Hispanics, and Asians. Interestingly, the higher percentage of Blacks in a county is associated with better health for Blacks, Hispanics, and Asians. However, it is associated with poor health for Whites. Whites and Hispanics who live in metropolitan areas tend to have worse health than those who live in non-metropolitan areas. In contrast, Blacks and Asians who live in metropolitan areas tend to have better health than those who live in non-metropolitan areas. However, the health of AIANs is not associated with any neighborhood characteristics, presumably because more than $75 \%$ of them live in isolated small towns and rural areas away from their own communities. These results indicate that public health initiatives targeting neighborhoods may have different impact on different groups of the population.

Seventy-two percent of health disparity between non-Hispanic Whites and Blacks is attributable to Blacks' relatively inferior values of the socio-economic and neighborhood factors, whereas, for Hispanics, the percentage is only $50 \%$. Sixty-five percent of the disparity between American Indians and Alaska Natives and non-Hispanic Whites is attributed to endowments in favor of Whites.

The most remarkable finding from the decomposition analysis is that college education is by far the most powerful instrument in reducing health disparity across all groups. From policy standpoint, as Case and Deaton (2020) have pointed out, higher education is not a suit of armor that protects a person from health shocks. Rather, high education may lead individuals to take better care of themselves by choosing less hazardous occupations, better neighborhoods, and healthy behaviors, which protect their health. These considerations suggest that higher-educated adults appear to effectively marshal their personal resources to avoid disease and premature death by taking preventative measures and making healthy choices. In lacking this 'personal firewall,' their less-educated peers are more reliant on social resources for health protection. For the latter group, the characteristics of the local area and available social resources become more important. These considerations are borne out quite well in our analysis.

The underlying basis for many of these documented factors contributing the racial/ ethnic health disparities and the associated policy recommendations need to be probed further. For instance, what are the specific pathways by which Blacks do better in metropolitan areas? Do they do better because they have better access to health care due to better transportation, jobs, recreational facilities, and availability of minority physicians? However, why are Hispanics not doing better in metropolitan areas as well? More generally, we should study how specific neighborhood characteristics work on the health of specific minority groups. Even though additional evidence on the underlying pathways will be helpful, our findings nevertheless suggest that public health initiatives to eliminate health disparity should be targeted differently for different racial/ethnic groups by focusing on the most consequential characteristics for each racial/ethnic group. Not all minorities are the same in terms of their health, and the disparities within each group are as important as disparities across groups. Neighborhood characteristics seem to generate much of the 
health disparities between groups. This distinction between within- and between-group health disparities, first emphasized by Lahiri and Pulungan (2007), is not well-recognized among public health analysts, and needs to be communicated better. Unfortunately, our analysis suggests there is no 'silver bullet' that can eliminate minority health disparities in the immediate future.

Author Contributions: Conceptualization, K.L. and Z.P.; methodology, K.L. and Z.P.; software, Z.P.; validation, K.L. and Z.P.; formal analysis, K.L. and Z.P.; investigation, K.L. and Z.P.; resources, KL.; data curation, Z.P.; writing—original draft preparation, Z.P.; writing—review and editing, K.L.; visualization, Z.P.; supervision, K.L.; project administration, K.L.; funding acquisition, K.L. Both authors have read and agreed to the published version of the manuscript.

Funding: This research was supported by the National Center on Minority Health and Health Disparities, National Institutes Funding: of Health (grant number P20MD003373). The content is solely the authors' responsibility and does not necessarily represent the National Center on Minority Health and Health Disparities or the National Institutes of Health's official views.

Data Availability Statement: https:/ / www.cdc.gov/brfss/index.html (accessed on 5 May 2021).

Acknowledgments: We thank two anonymous referees for providing many helpful comments. An early version of the paper was presented at the 8th World Congress of Health Economics organized by iHEA.

Conflicts of Interest: The authors declare no conflict of interest.

\section{Appendix A}

\section{Descriptive Statistics}

Socio-demographic variables. The average age of respondents is 45 years. On average, Whites are the oldest ( 47 years), and Asians are the youngest (39 years). The percentage of male varies from $46 \%$ for Blacks to $55 \%$ for Asians. Sixty-three percent of Whites are married compared to only $40 \%$ of Blacks. The distribution of education level varies considerably among racial/ethnic groups. Only $16 \%$ of Hispanics have 4 years of college or higher, while $58 \%$ of Asians and $33 \%$ of Whites have that level of education. The distribution of employment status notably differs among racial/ethnic groups. For instance, the percentage of respondents unable to work varies from $1.5 \%$ for Whites to $9.6 \%$ for AIANs. Annual household income also varies considerably among racial/ethnic groups. AIANs have the lowest average annual household income, which is $\$ 35,410$, while Asians have the highest $(\$ 62,570)$.

Eighty-six percent of the respondents have a health plan, in which Hispanics have the lowest percentage $(70 \%)$, while Whites have the highest percentage $(89 \%)$. Similar to having a health plan, the percentage of respondents who could not afford to see a doctor at least once in the past 12 months also varies considerably from 9\% for Asians to 20\% for AIANs.

Bad health habits. The percentage of smokers varies noticeably among racial/ethnic groups from $14 \%$ for Asians to $37 \%$ for AIANs.

Self-assessed health (SAH) status. Figure A1 presents the distribution of SAH by race/ethnicity. Twenty-three percent of the respondents considered their health status as excellent, while only $4 \%$ considered poor. Among racial/ethnic groups, the distribution varies considerably. The percentage of excellent and very good health is higher in Whites than in Blacks, Hispanics, and AIANs. Figure A2 presents the distribution of SAH by income levels. The figure indicates that as income increases, the percentage of excellent health increases, and the percentage of poor health decreases. This pattern indicates a strong association between income and health. 


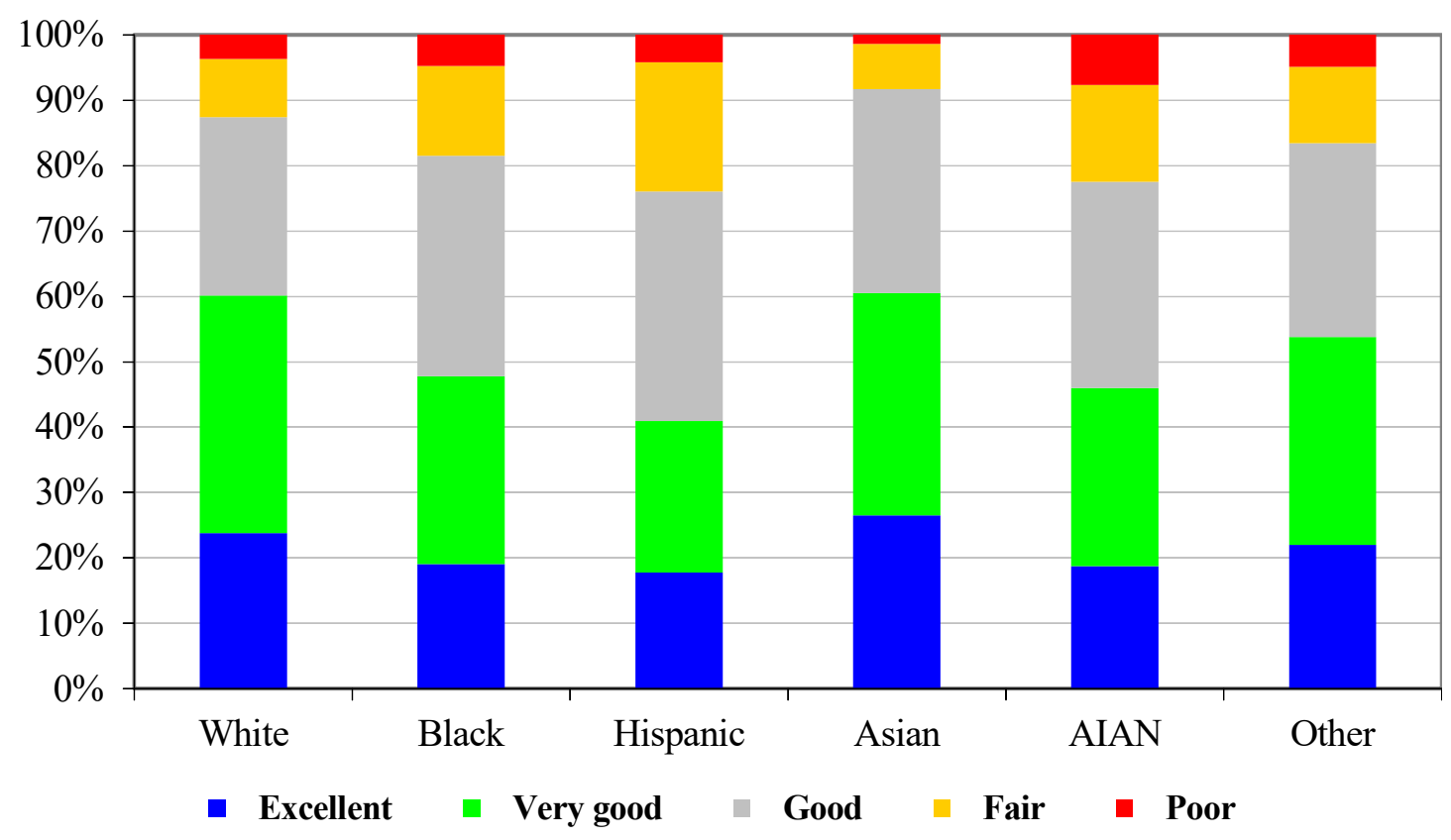

Figure A1. Distribution of SAH status by race/ethnicity.

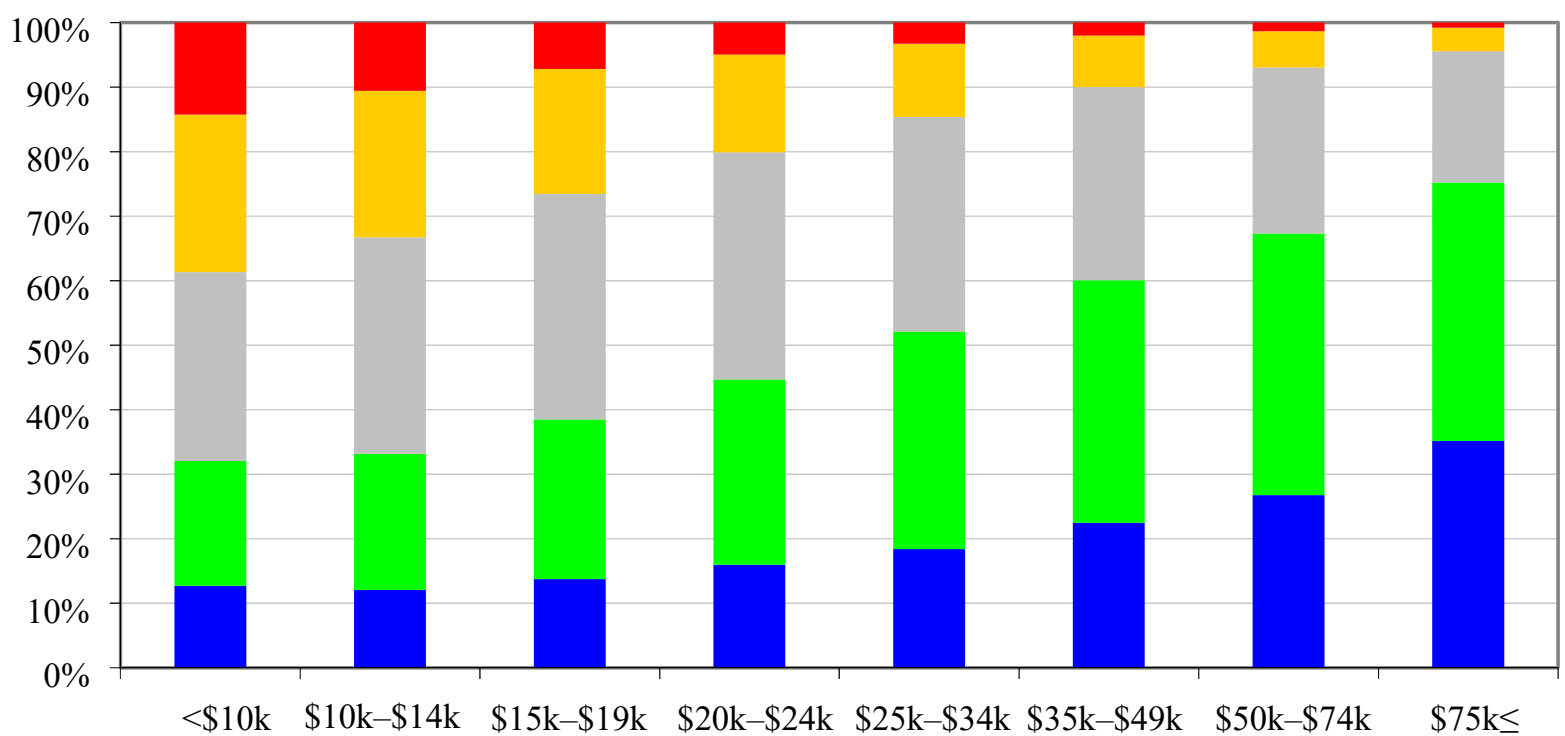

- Excellent $\square \quad$ Very good $\square$ Good $\square$ Fair $\square$ Poor

Figure A2. Distribution of SAH status by income groups.

Table A1. Descriptive statistics by race/ethnicity.

\begin{tabular}{lccccccc}
\hline \multirow{2}{*}{\multicolumn{1}{c}{ Variable }} & \multicolumn{9}{c}{ Race/Ethnicity } \\
\cline { 2 - 8 } & $\mathbf{N}$ & All & White & Black & Hispanic & Asian & AIAN \\
\hline Reported age in years & $1,212,890$ & 45.07 & 46.81 & 42.23 & 39.14 & 38.82 & 42.51 \\
\hline Gender (male $=1$ ) & $1,212,890$ & 0.494 & 0.495 & 0.448 & 0.507 & 0.547 & 0.534 \\
\hline Marital status & $1,212,889$ & 0.591 & 0.626 & 0.391 & 0.552 & 0.610 & 0.506 \\
\hline
\end{tabular}


Table A1. Cont.

\begin{tabular}{|c|c|c|c|c|c|c|c|}
\hline \multirow{2}{*}{ Variable } & \multicolumn{7}{|c|}{ Race/Ethnicity } \\
\hline & $\mathbf{N}$ & All & White & Black & Hispanic & Asian & AIAN \\
\hline Education: & $1,212,890$ & & & & & & \\
\hline Grade 8 or less & & 0.041 & 0.020 & 0.035 & 0.169 & 0.010 & 0.048 \\
\hline Grades 9-11 (Some high school) & & 0.076 & 0.060 & 0.110 & 0.145 & 0.031 & 0.128 \\
\hline Grade 12 or GED (High school graduate) & & 0.307 & 0.308 & 0.361 & 0.298 & 0.162 & 0.349 \\
\hline College 1 year to 3 years & & 0.274 & 0.282 & 0.289 & 0.227 & 0.221 & 0.297 \\
\hline College 4 years or more & & 0.302 & 0.331 & 0.205 & 0.162 & 0.576 & 0.178 \\
\hline Employment: * & $1,211,418$ & & & & & & \\
\hline Employed for wages & & 0.551 & 0.543 & 0.578 & 0.569 & 0.601 & 0.519 \\
\hline Self-employed & & 0.085 & 0.091 & 0.057 & 0.074 & 0.076 & 0.093 \\
\hline Out of work for more than 1 year & & 0.016 & 0.013 & 0.032 & 0.023 & 0.022 & 0.028 \\
\hline Out of work for less than 1 year & & 0.031 & 0.024 & 0.054 & 0.047 & 0.039 & 0.044 \\
\hline A homemaker & & 0.074 & 0.073 & 0.033 & 0.115 & 0.063 & 0.060 \\
\hline A student & & 0.044 & 0.038 & 0.053 & 0.053 & 0.115 & 0.044 \\
\hline Retired & & 0.159 & 0.184 & 0.124 & 0.071 & 0.069 & 0.118 \\
\hline Unable to work & & 0.039 & 0.033 & 0.071 & 0.047 & 0.015 & 0.096 \\
\hline Annual Household Income $(\$ 1000) *$ & $1,068,122$ & 52.88 & 57.53 & 39.41 & 35.41 & 62.57 & 40.80 \\
\hline Have health plan & $1,212,890$ & 0.859 & 0.894 & 0.808 & 0.701 & 0.869 & 0.765 \\
\hline Smoking & $1,212,890$ & 0.223 & 0.229 & 0.225 & 0.186 & 0.142 & 0.373 \\
\hline Self-assessed health status: & $1,212,890$ & & & & & & \\
\hline Excellent & & 0.226 & 0.238 & 0.191 & 0.178 & 0.265 & 0.188 \\
\hline Very good & & 0.338 & 0.364 & 0.287 & 0.232 & 0.340 & 0.272 \\
\hline Good & & 0.291 & 0.273 & 0.338 & 0.351 & 0.312 & 0.316 \\
\hline Fair & & 0.108 & 0.089 & 0.137 & 0.198 & 0.069 & 0.148 \\
\hline Poor & & 0.038 & 0.037 & 0.048 & 0.042 & 0.014 & 0.077 \\
\hline
\end{tabular}

(a): Coefficient estimates of the scale function to control for heteroskedasticity

\begin{tabular}{|c|c|c|c|}
\hline Variable & Coefficient Estimate & Standard Error & $p$-value \\
\hline Gender $($ male = 1) & 0.1804 & 0.0076 & 0.0000 \\
\hline Age 18-24 & -0.0376 & 0.0189 & 0.0473 \\
\hline Age 25-29 & -0.0767 & 0.0198 & 0.0001 \\
\hline Age 30-34 & -0.0882 & 0.0193 & 0.0000 \\
\hline Age 35-39 & -0.0792 & 0.0182 & 0.0000 \\
\hline Age $40-44$ & -0.0873 & 0.0180 & 0.0000 \\
\hline Age $45-49$ & -0.0466 & 0.0181 & 0.0102 \\
\hline Age 55-59 & 0.1123 & 0.0176 & 0.0000 \\
\hline Age 60-64 & 0.1879 & 0.0178 & 0.0000 \\
\hline Age 65-69 & 0.1937 & 0.0194 & 0.0000 \\
\hline Age 70-74 & 0.2423 & 0.0185 & 0.0000 \\
\hline Age 75-79 & 0.3340 & 0.0188 & 0.0000 \\
\hline Age 80-84 & 0.4545 & 0.0216 & 0.0000 \\
\hline Age $\geq 85$ & 0.6140 & 0.0267 & 0.0000 \\
\hline Black & 0.3515 & 0.0121 & 0.0000 \\
\hline Hispanic & 0.4024 & 0.0120 & 0.0000 \\
\hline Asian & 0.3715 & 0.0237 & 0.0000 \\
\hline AIAN & 0.4308 & 0.0247 & 0.0000 \\
\hline Annual Household Income $(\$ 1000)$ & -0.0031 & 0.0002 & 0.0000 \\
\hline Having health plan & -0.1716 & 0.0126 & 0.0000 \\
\hline Education higher than high school & -0.1647 & 0.0086 & 0.0000 \\
\hline
\end{tabular}

Source: Calculated from BRFSS 1999-2014. Note: * Sample sizes (Ns) for employment status and annual household income are smaller due to missing values. Those missing values were imputed using multiple-imputation algorithm before estimating the regression models; the descriptive statistics of employment status and annual household income after adding imputed values are almost the same as the descriptive statistics before adding those imputed values. 
Table A2. A decomposition analysis of health disparity between whites and minorities.

\begin{tabular}{|c|c|c|c|c|c|c|c|c|c|c|}
\hline \multirow[b]{2}{*}{ Component } & & \multicolumn{3}{|c|}{ Black } & \multicolumn{3}{|c|}{ Hispanic } & \multicolumn{3}{|c|}{ AIAN } \\
\hline & & Endowment & Coef. & Total & Endowment & Coef. & Total & Endowment & Coef. & Total \\
\hline Intercept & $\%$ & & 30.1 & 30.1 & & 39.7 & 39.7 & & -27.7 & -27.7 \\
\hline Age $25-29$ & $\%$ & 0.6 & -1.6 & -1.0 & 1.0 & -0.4 & 0.6 & 0.4 & 0.3 & 0.7 \\
\hline Age 30-34 & $\%$ & 0.7 & -1.4 & -0.7 & 1.3 & 0.1 & 1.4 & 0.2 & 1.8 & 1.9 \\
\hline Age 35-39 & $\%$ & 0.5 & -1.1 & -0.6 & 1.2 & 0.8 & 2.0 & 0.2 & 4.2 & 4.4 \\
\hline Age 40-44 & $\%$ & 0.2 & 2.1 & 2.3 & -0.3 & 0.9 & 0.6 & 0.4 & 4.5 & 4.9 \\
\hline Age 45-49 & $\%$ & 0.2 & 4.5 & 4.7 & -1.1 & 1.5 & 0.4 & -0.3 & 5.2 & 5.0 \\
\hline Age 50-54 & $\%$ & -1.2 & 5.1 & 3.9 & -2.6 & 0.9 & -1.7 & -1.1 & 3.3 & 2.2 \\
\hline Age 55-59 & $\%$ & -1.8 & 4.3 & 2.5 & -3.2 & 0.8 & -2.4 & -0.3 & 3.2 & 2.8 \\
\hline Age 60-64 & $\%$ & -1.3 & 3.6 & 2.4 & -2.9 & 0.3 & -2.7 & -0.3 & 2.2 & 1.9 \\
\hline Age 65-69 & $\%$ & -1.6 & 2.5 & 0.9 & -3.6 & -0.3 & -3.9 & -1.2 & 1.2 & 0.1 \\
\hline Age 70-74 & $\%$ & -4.0 & 0.4 & -3.5 & -4.3 & -0.2 & -4.6 & -3.7 & -0.1 & -3.8 \\
\hline Age 75-79 & $\%$ & -5.5 & 0.0 & -5.4 & -4.9 & -0.4 & -5.3 & -4.7 & -0.8 & -5.5 \\
\hline Age $80-84$ & $\%$ & -3.6 & -0.3 & -3.8 & -3.4 & -0.2 & -3.6 & -2.5 & -0.4 & -2.9 \\
\hline Age $\geq 85$ & & -1.8 & 0.0 & -1.8 & -1.9 & -0.1 & -1.9 & -1.0 & 0.0 & -1.0 \\
\hline Gender $($ male $=1)$ & $\%$ & -1.2 & -26.1 & -27.3 & 0.3 & -14.2 & -13.9 & 0.4 & -16.7 & -16.3 \\
\hline Smoking & $\%$ & 0.2 & -6.9 & -6.7 & -2.2 & -5.0 & -7.1 & 8.0 & -8.5 & -0.5 \\
\hline Marital status & $\%$ & 2.8 & -0.2 & 2.6 & 0.5 & 3.7 & 4.2 & 1.1 & -1.8 & -0.7 \\
\hline Grades 9-11 (Some high school) & $\%$ & -2.0 & -1.4 & -3.4 & -2.8 & -2.8 & -5.6 & -2.0 & 1.3 & -0.8 \\
\hline $\begin{array}{l}\text { Grade } 12 \text { or GED (High school } \\
\text { graduate) }\end{array}$ & $\%$ & -7.8 & 8.6 & 0.7 & -1.3 & -3.7 & -5.0 & -5.2 & 7.0 & 1.8 \\
\hline College 1 year to 3 years & $\%$ & -3.0 & 11.7 & 8.7 & 6.3 & -4.5 & 1.9 & -2.6 & 10.9 & 8.3 \\
\hline $\begin{array}{l}\text { College } 4 \text { years or more (College } \\
\text { graduate) }\end{array}$ & $\%$ & 32.5 & 14.0 & 46.6 & 32.5 & -1.7 & 30.8 & 27.2 & 9.9 & 37.1 \\
\hline Self-employed & $\%$ & 1.5 & 1.2 & 2.6 & 0.6 & 0.0 & 0.6 & -0.2 & 1.1 & 0.9 \\
\hline Out of work & $\%$ & 3.5 & -1.7 & 1.8 & 1.9 & -2.2 & -0.3 & 1.5 & -2.1 & -0.6 \\
\hline Homemaker & $\%$ & 0.0 & 0.8 & 0.8 & 0.0 & 1.3 & 1.3 & 0.0 & 0.8 & 0.8 \\
\hline Student & $\%$ & -0.3 & 0.8 & 0.5 & -0.1 & 0.0 & -0.2 & -0.2 & 1.2 & 1.0 \\
\hline Retired & $\%$ & -2.8 & 4.3 & 1.5 & -4.3 & 0.5 & -3.9 & -2.2 & 5.4 & 3.2 \\
\hline Unable to work & $\%$ & 19.3 & -10.6 & 8.7 & 3.7 & -4.0 & -0.3 & 21.9 & -4.6 & 17.3 \\
\hline Having health plan & $\%$ & 0.8 & -11.5 & -10.7 & 1.5 & -17.6 & -16.0 & 1.0 & 1.3 & 2.2 \\
\hline Income pc $\$ 10 \mathrm{k}-\$ 15 \mathrm{k}$ & $\%$ & -2.9 & 2.0 & -0.9 & -2.5 & -2.0 & -4.5 & -2.1 & 1.2 & -0.9 \\
\hline Income pc $\$ 15 \mathrm{k}-\$ 20 \mathrm{k}$ & $\%$ & -2.6 & 4.0 & 1.4 & -0.6 & -1.2 & -1.8 & -1.8 & 1.6 & -0.3 \\
\hline Income pc $\$ 20 \mathrm{k}-\$ 25 \mathrm{k}$ & $\%$ & -0.1 & 4.1 & 4.0 & 2.3 & -1.9 & 0.4 & -0.6 & -1.4 & -1.9 \\
\hline Income pc $\$ 25 \mathrm{k}-\$ 35 \mathrm{k}$ & $\%$ & 6.4 & 6.4 & 12.8 & 7.5 & -1.6 & 5.9 & 4.8 & 0.8 & 5.6 \\
\hline Income pc $\$ 35 \mathrm{k}-\$ 50 \mathrm{k}$ & $\%$ & 7.7 & 3.3 & 11.0 & 8.3 & -1.0 & 7.3 & 4.7 & -1.7 & 3.1 \\
\hline Income pc $\$ 50 \mathrm{k}-\$ 75 \mathrm{k}$ & $\%$ & 16.6 & 4.5 & 21.1 & 13.1 & -1.1 & 12.0 & 12.8 & -0.1 & 12.6 \\
\hline Income $\mathrm{pc} \geq \$ 75 \mathrm{k}$ & $\%$ & 15.4 & 1.6 & 17.0 & 11.7 & -0.7 & 11.0 & 10.6 & -0.9 & 9.8 \\
\hline County median household income & $\%$ & 2.8 & -11.4 & -8.6 & 1.0 & 22.1 & 23.1 & 2.1 & 37.7 & 39.9 \\
\hline County income inequality & $\%$ & 0.8 & 13.1 & 13.9 & 1.0 & 24.8 & 25.8 & 0.4 & 0.2 & 0.5 \\
\hline County percent Black & $\%$ & 1.5 & -16.7 & -15.2 & 0.0 & -3.1 & -3.1 & 0.0 & -1.1 & -1.1 \\
\hline County percent Hispanic & $\%$ & -0.6 & 0.3 & -0.4 & -4.6 & 15.3 & 10.7 & -0.4 & 0.8 & 0.4 \\
\hline $\begin{array}{l}\text { County of metro areas of } 1 \text { million or } \\
\text { more population }\end{array}$ & $\%$ & 1.8 & -14.0 & -12.2 & 1.3 & 7.0 & 8.3 & -0.7 & -3.9 & -4.6 \\
\hline Total & & 71.8 & 28.3 & 100.0 & 50.3 & 49.6 & 99.9 & 64.5 & 35.5 & 100.0 \\
\hline
\end{tabular}

Note: A positive sign indicates an advantage for Whites, and a negative sign indicates an advantage for a minority group.

\section{Notes}

1 The terms "disparity" and "inequality" are used interchangeably in this paper.

2 We found that between $40 \%$ and $50 \%$ of the total health inequality in our sample is due to income-related health inequality - an estimate that is much higher than 25\% reported by Wagstaff and van Doorslaer (2004) for Canada.

3 See, for instance, Williams and Collins (1995), Ayanian et al. (1999), and Shishehbor et al. (2006).

4 One should be cautious about interpreting the contribution of each dummy coefficient in Table A2 since it is sensitive to the reference point selected in defining the dummy. However, the total contribution of a group of coefficients is not sensitive to the reference point. For example, the contribution of the coefficient of dummy for "unable to work" with "employed" as the reference point will be different from its contribution with "out of work" as the reference.

\section{References}

Adams, Peter, Michael Hurd, Daniel McFadden, Angela Merrill, and Tiago Ribeiro. 2003. Healthy, wealthy, and wise? Tests for direct causal between health and socioeconomic status. Journal of Econometrics 112: 3-56. [CrossRef]

Adler, Nancy E., and Katherine Newman. 2002. Socioeconomic health disparities: Pathways and policies. Health Affairs 21: 60-76. [CrossRef]

Adler, Nancy E., and Joan M. Ostrove. 1999. SES and health: What we know and what we do not. Annals of the New York Academy of Sciences 896: 3-5. [CrossRef] [PubMed]

Ayanian, John Z., Joel S. Weissman, Scotte Chasan-Taber, and Arnold M. Epstein. 1999. Quality of care by race and gender for congestive heart failure and pneumonia. Medical Care 37: 1260-69. [CrossRef]

Blinder, Alan. 1973. Wage Discrimination: Reduced Form and Structural Estimates. Journal of Human Resources 7: 436-55. [CrossRef] 
Bommier, Antoine, and Guy Stecklov. 2002. Defining health inequality: Why Rawls succeeds where social welfare theory fails. Journal of Health Economics 21: 497-513. [CrossRef]

Bruner, Deborah W., Michele Jones, David Buchanan, and Jose Russo. 2006. Reducing cancer disparities for minorities: A multidisciplinary research agenda to improve patient access to health systems, clinical trials, and effective cancer therapy. Journal of Clinical Oncology 24: 2209-15. [CrossRef]

Case, Anne, and Angus Deaton. 2020. Deaths of Despair and the Future of Capitalism. Princeton: Princeton University Press.

Centers for Disease Control and Prevention (CDC). 1999-2014. Behavioral Risk Factor Surveillance System Survey Questionnaire; Atlanta: U.S. Department of Health and Human Services, Centers for Disease Control and Prevention.

Centers for Disease Control and Prevention (CDC). 2013. Health Disparities and Inequalities Report (CHDIR)—United States. MMWR 62. Available online: https://www.cdc.gov/minorityhealth/chdir/index.html (accessed on 28 April 2021).

Charasse-Pouélé, Cecile, and Martin Fournier. 2006. Health disparities between racial groups in South Africa: A decomposition analysis. Social Science E Medicine 62: 2897-914.

Cutler, David M., and Adriana Lleras-Muney. 2006. Education and Health: Evaluating Theories and evidence. In National Bureau of Economic Research Working Paper 12352. Cambridge: National Bureau of Economic Research.

Cutler, David M., and Elizabeth Richardson. 1997. Measuring the health of the U.S. population. Brooking Papers on Economic Activity. Microeconomics 1997: 217-71. [CrossRef]

Cutler, David M., and Elizabeth Richardson. 1998. The value of health: 1970-1990. American Economic Review 88: 97-100.

Cutler, David M., Angus Deaton, and Adriana Lleras-Muney. 2006. The determinants of mortality. Journal of Economic Perspectives 20: 97-120. [CrossRef]

Deaton, Angus. 2006. Global pattern of income and health: Facts, interpretation, and policies. In National Bureau of Economic Research Working Paper 12735. Cambridge: National Bureau of Economic Research.

Deaton, Angus, and Darren Lubotsky. 2003. Mortality, inequality, and race in American cities and states. Social Science E Medicine 56: 1139-53.

Diez-Roux, Ana. V., F. Javier Nieto, Laura Caulfield, Hermonn A. Tyroler, Robert L. Watson, and Moyses Szklo. 1999. Neighborhood differences in diet: The Atherosclerosis Risk in Communities (ARIC) study. Journal of Epidemiology and Community Health 53: 55-63. [CrossRef]

Ecob, Russell, and Sally MacIntyre. 2000. Small area variations in health-related behaviors: Do these depend on the behavior itself, its measurement, or on personal characteristics? Health $\mathcal{E}$ Place 6: 261-74.

Fairlie, R. W. 1999. The absence of the African-American owned business: An analysis of the dynamics of self-employment. Journal of Labor Economics 17: 80-108. [CrossRef]

Fairlie, Robert W. 2005. An Extension of the Blinder-Oaxaca decomposition technique to Logit and Probit models. Journal of Economic and Social Measurement 30: 305-16. [CrossRef]

Fiscella, Kevin, Peter Franks, Mark P. Doescher, and Barry G. Saver. 2002. Disparity in health care by race, ethnicity, and language among the insured: Findings from a national sample. Medical Care 40: 52-9. [CrossRef] [PubMed]

Gomulka, Joanna, and Nicholas Stern. 1990. The employment of married woman in the United Kingdom 1970-1983. Economica 57: 171-99. [CrossRef]

Groot, Wim. 2000. Adaptation and scale of reference bias in self-assessments of quality of life. Journal of Health Economics 19: 403-20. [CrossRef]

Health Resources and Services Administration. 2009. Area Resource File; (ARF 2008 release). Washington, DC: U.S. Department of Health and Human Services.

Hodgson, David C., Charles S. Fuchs, and John Z. Ayanian. 2001. Impact of patient and provider characteristics on the treatment and outcomes of colorectal cancer. Journal of the National Cancer Institute 93: 501-15. [CrossRef] [PubMed]

Humphries, Karin H., and Eddy van Doorslaer. 2000. Income-related health inequality in Canada. Social Science Medicine 50: 663-71. [CrossRef]

Idler, Ellen L., and Yael Benyamini. 1997. Self-rated health and mortality: A review of twenty-seven community studies. Journal of Health and Social Behavior 38: 21-37. [CrossRef]

Institute of Medicine. 2002. Unequal Treatment: Controlling Racial and Ethnic Disparities in Health Care. Washington, DC: National Academies Press.

Kennedy, Bruce P., Ichiro Kawachi, Roberto Glass, and Deborah Prothrow-Stith. 1998. Income distribution, socioeconomic status, and self-rated health in the United States: Multilevel analysis. BMJ 317: 917-21. [CrossRef]

Lahiri, Kajal, and Jijye Kim. 2021. American HALE at Midlife: An Analysis Based on HRS, under submission for publication.

Lahiri, Kajal, and Zulkarnain Pulungan. 2007. Income Related Health Disparity and Its Determinants in New York State: Racial/Ethnic and Geographical Comparisons. In Toward Equity in Health: A New Global Approach to Inequities in Health. Edited by Barbara Wallace. Berlin/Heidelberg: Springer, pp. 97-127.

Lahiri, Kajal, Denton R. Vaughan, and Bernard Wixon. 1995. Modeling SSA's sequential disability determination process using matched SIPP data. Social Security Bulletin 58: 1-41.

Lee, A. James, Lee Analytics, Colin S. Baker, Stephen Gehlbach, David Hosmer, and Monika Reti. 1998. Do black elderly Medicare patients receive fewer services? An analysis of the procedure used for selected patient conditions. Medical Care Research and Review 55: 314-33. [CrossRef] 
Manor, Orly, Shirley Matthews, and Chris Power. 2001. Self-rated health and limiting longstanding illness: Inter-relationships with morbidity in early adulthood. International Journal of Epidemiology 30: 600-7. [CrossRef]

McKelvey, Richard, and William Zavoina. 1975. A statistical model for the analysis of ordinal level-dependent variables. Journal of Mathematical Sociology 4: 103-20. [CrossRef]

Oaxaca, Ronald. 1973. Male-Female Wage Differentials in Urban Labor Market. International Economic Review 14: 693-709. [CrossRef]

Rawls, John. 1971. A Theory of Justice. Cambridge: Harvard University Press.

Rubin, Donald B. 1987. Multiple Imputation for Nonresponse in Surveys. New York: John Wiley.

Safaei, Jahl. 2007. Income and health inequality across Canadian provinces. Health E Place 13: 629-38.

Schafer, Joseph L. 1997. Analysis of Incomplete Multivariate Data. New York: Chapman and Hall.

Shishehbor, Mehdi H., David Litaker, Claire E. Pothier, and Michael S. Lauer. 2006. Association of socioeconomic status with functional capacity, heart rate recovery, and all-cause mortality. Journal of American Medical Association 295: 784-92. [CrossRef]

Sickles, Robin C., and Paul Taubman. 1997. Mortality and morbidity among adults and elderly. In Handbook of Population and Family Economics. Edited by Mark R. Rosenzweig and Oded Stark. Amsterdam: North-Holland, pp. 559-643.

Soobader, Mah-J., and Felicia B. LeClere. 1999. Aggregation and the measurement of income inequality: Effects on morbidity. Social Science E Medicine 48: 733-44.

Subramanian, Sabu V., and Ichiro Kawachi. 2003. The association between state income inequality and worse health is not confounded by race. International Journal of Epidemiology 32: 1022-28. [CrossRef]

Subramanian, Sabu V., and Ichiro Kawachi. 2004. Income inequality and health: What have we learned so far? Epidemiologic Reviews 26: 78-91. [CrossRef] [PubMed]

Subramanian, Sabu V., and Ichiro Kawachi. 2006. Whose health is affected by income inequality? A multilevel interaction analysis of contemporaneous and lagged effects of state income inequality on individual self-rated health in the United States. Health $\mathcal{E}$ Place 12: $141-56$.

U.S. Department of Health and Human Services (US-DHHS). 2020. Healthy People 2020; Washington, DC: US-DHHS. Available online: https: / / www.cdc.gov/nchs/healthy_people/hp2020.htm (accessed on 3 April 2021).

Van Doorslaer, Eddy, and Andrew M. Jones. 2003. Inequalities in self-reported health: Validation of a new approach to measurement. Journal of Health Economics 22: 61-87. [CrossRef]

Van Ourti, Tom, Eddy van Doorslaer, and Xander Koolman. 2006. The Effect of Growth and Inequality in Incomes on Health Inequality: Theory and Empirical Evidence from the European Panel. Tinbergen Institute Discussion Paper, TI 2006-108/3. Rotterdam: Erasmus University.

Wagstaff, Adam, and Eddy van Doorslaer. 2004. Overall versus socioeconomic health inequality: A measurement framework and two empirical illustrations. Health Economics 13: 297-301. [CrossRef]

Wenzlow, Audra T., John Mullahy, and Barbara L. Wolfe. 2004. Understanding Racial Disparity in Health: The Income-Wealth Paradox. Discussion Paper No. 1283-04. Madison: Institute on Research on Poverty, University of Wisconsin.

Wilkinson, Richard G. 1992. Income distribution and life expectancy. British Medical Journal 304: 165-68. [CrossRef]

Wilkinson, Richard G., and Kate E. Pickett. 2006. Income inequality and population health: A review and explanation of the evidence. Social Science \& Medicine 62: 1768-84.

Williams, David R., and Chiquita Collins. 1995. US socioeconomic and racial differences in health: Patterns and explanations. Annual Review of Sociology 21: 349-86. [CrossRef] 